\title{
The influence of regional autonomist government on the territory environmental and economic performances
}

\author{
G. Skonieczny \& B. Torrisi \\ Department of Economics and Territory, \\ Branch of Economic Statistics, University of Catania, Italy
}

\begin{abstract}
In the last decade there's been a growing interest in the Regions with special autonomy, in particular from a political point of view, and less from a scientific one.

In Italy, some Regions were given special autonomy after the coming into force of the Republican Constitution. In Spain, such regions are called "Comunidades Autònomas". They are similar to the Italian Regions, but with big differences concerning their provisions and power to make decisions.

The few scientific contributions available have analysed these territorial structures mainly from a normative and managerial point of view. Some sporadic attempts at economic analysis have been made, but always from a merely theoretical point of view.

In this context, there seems to be a lot of space for the development of a trend of research aiming at a quantitative analysis of these regions, in comparison with less autonomist areas. Such quantitative investigations on the competitiveness, socio-economic development, quality of life, social welfare, and environmental performance of these areas with special autonomy, are issues still open and not entirely analysed.

As a consequence of this void in the research, the present contribution aims at analysing how much influence the autonomy of a territory can have on the changes in its performances. We've taken into consideration some Italian and Spanish regions (both with special autonomy and not).

In order to attain this objective, we have used those statistical indicators that can synthesise the above mentioned aspects and point out the similarities and dissimilarities among the considered areas between 1995 and 2006. From the methodological point of view, we have used the multi-varied analysis techniques, in order to analyse the territorial homogeneities and heterogeneities, and the parametric and non-parametric tests, to verify whether, some conditions being equal, the autonomist aspect can produce changes in the performances of the analysed territories.
\end{abstract}

Keywords: regions with special autonomy, classification, graduation, territorial comparisons. 


\section{Introduction}

The competitiveness of an area, its economic, social, and environmental development, its quality of life and welfare, represent the main attractive aspects of a territory.

In this context, it seems possible to assume that more autonomous systems of a territory government, than the standard of the country it belongs to, can create more wealth, more control of the territory, better environmental development, and therefore, better conditions of life.

There are few scientific contributions aiming at verifying such thesis; they are mainly theoretical, not empirical.

As a consequence of this void in the research, the present contribution aims at analysing how much influence can the autonomy of a territory have on the changes in its performances.

In order to attain this objective, we have used those statistical indicators that can synthesise the above mentioned aspects and point out the similarities and dissimilarities among the considered areas between 1995 and 2006. Moreover, the graduation techniques and the non-parametric statistical tests have generated the conclusive analyses of this work.

\section{The sources, the data, and the indicators}

The starting point of this analysis is the collection of data and the selection of the indicators used. The latter include:

\section{- Environment}

Public water provided per capita - Rubbish collection per capita - \% of rubbish going to final distribution

\section{- Economic Aggregates}

Gross value added to basic prices per branch - A B Agriculture, hunting, forestry and fishing - C_E Mining and quarrying, manufacturing and electricity F Construction - G_H_I Wholesale and retail trade, repair of motor vehicles, motorcycles and personal and household goods; hotels and restaurants; transport, storage and communication - J_K Financial intermediation; real estate, renting and business activities - L_to_P Public administration and defence, compulsory social security - education; health and social work; other community, social and personal service activities; private households with employed persons

- GDP

GDP in SPA per inhabitant - Average growth of regional GDP in percentage

- Family Accounts

Per capita family income, in PPCS - Family income as percentage of GDP -

\section{- Employment and Unemployment}

Persons in employment - men (1000)/Male pop. Age 15-64 - Persons in employment - women (1000)/Female pop. Age 15-64 - Persons in employment full time (1000)/Persons in employment - total - Persons in employment - part time (1000)/Persons in employment - total 


\section{- Unemployment}

Total - Female - $<25$ years old - Long term unemployment as $\%$ of unemployment. - Trend in unemployment rate, average annual increase (\%) Trend for unemployed people, average annual increase (\%) - Trend in workforce, average annual increase $(\%)$

\section{- Population}

Born ( $\%$ oo - Dead ( $\%$ oo - Net migration ( $\%$ oo) - Change of population $(\%$ oo) Density of population - Birth-rate - Death-rate per 1000 inhabitants, 1000 Population natural increase rate - Young age dependency ratio $(0-19)(20-59)$ - Old age dependency ratio $(60+)(20-59)$

\section{- Transport}

Railways $(\mathrm{km})$ total/territory - Railways with more than double quantity of lines $(\mathrm{km}) /$ tot railways - Railways - electrical lines/tot railways - Motorways $(\mathrm{km}) /$ territory - Other roads $(\mathrm{Km})$ /territory - Number of deaths per million of inhabitants

\section{- Tourism}

Establishments/total establishments - Bedspace/establishments - Arrivals of residents /tot arrivals - Arrivals of non-residents/tot arrivals - Nights spent by residents/tot nights - Nights spent by non-residents/tot nights.

The data used have been taken from the classification of European regional areas NUTS 2 (European Commission Regions, 2003 and 2007 - Atkinson et al. 2001, Guarini 1998). In particular, we will refer to 208 regions of the EU-15 for 1995, and to 343 regions of the EU-27 for 2006, classified on the base of 48 indicators (variables).

The first selection of variables has been determined from the uniformity and completeness of the data matrixes in comparison with the considered variables. Some indicators have been cancelled because of the series incompleteness (75 out of 123). In all, we have created a data base of 208 regions (year 1995) and 343 regions (year 2006) for 48 referred variables expressing environmental, social, and economic development.

The use of such indicators has provided the first information on the environmental, social, and economic development of the analysed territory.

\section{The methodology employed}

The 208 and 343 regions have been classified through the metric procedure of classification k-means. (This procedure allows one to identify groups of relatively homogeneous cases in relation with the selected features, using an algorithm which can handle a great number of cases. Such algorithm needs the number of clusters.) In relation to the 48 indicators (as variables effect) chosen and selected with the principal components method. The cluster analysis allowed us to aggregate the homogeneities of the analysed territories in 5 clusters.

Since the simple aggregation has resulted in a little significant representation, in order to define a list of distances between one territorial unit and the others, it was necessary to build an algorithm GDM (Graduate Distance from Matrix). In particular, the procedure adopted to generate a comprehensive measure $d_{i}$ of the 
effect induced by environmental and economic development (where i represents the $i^{\text {th }}$ territorial unit), was based on the remodulation of some indicators according to the reciprocal calculus, as to generate a uniform datum reading for all the variables used. Then we standardised the variables in relation to the mean and the mean-square deviation. Moreover, we applied the PLS methods to the initially selected variables, in order to generate the loadings $p_{j}$ which have been used in the composition of the final indicator for each $\mathrm{j}^{\text {th }}$ variable.

The indicator we built is given by

$$
d_{i}=\sqrt{\sum_{i=1}^{n} \sum_{j=1}^{m}\left(x_{i j}-\min _{j}\right)^{2} p_{j}}
$$

where $x_{i}$ represents the standardised values in comparison with the $\mathrm{j}^{\text {th }}$ variable in relation to the $\mathrm{j}^{\text {th }}$ territorial unit, while $\min _{j}$ represents the minimum value of the distribution associated to the $\mathrm{j}^{\text {th }}$ variable.

The use of such indicator has allowed us to provide an assessment of the degree of environmental and economic development. Through $d_{i}$ we could generate a comprehensive classification of the 208 (1995) and 343 (2006) regional areas of European countries. Being the mere reading of the list quite simplistic in comparison with the initial objectives, we tried to represent the 5 clusters of the European regions according to the estimated level of the environmental and economic development. Assuming a scale of development degree divided into 5 classes (low, medium-low, medium, medium-high, high), we built a graphic representation of the quantities on the base of the following function:

$$
\beta=d_{i^{*}} \sigma_{k}
$$

where $\beta$ represents the distance from the centre (point of minimum estimated economic and environmental development), $d_{i}$ an increasing measure in comparison with the level of the environmental and economic development in the $\mathrm{i}^{\text {th }}$ region, and $\sigma_{k}$ an also increasing scale factor, while the angular coefficients have been considered uniform. The scale factor $\sigma_{k}$ represents the mean-square deviations between the territorial units of $d_{i}$ in comparison with the mean $M_{d k}$ :

$$
\sigma_{k}=\sqrt{\frac{1}{k} \sum_{i=1}^{k}\left(d_{i}-M_{d k}\right)^{2}}
$$

where $M_{d k}$ represents the arithmetic mean of the levels $d_{i}$ for each $i=1 \ldots n$ and $k=2 \ldots n-1$. By using such criterion, it was possible to represent the classification of the 208 regional areas on the base of the environmental and economic development, estimated $d_{i}$ within each class of level, which could extrapolate the closest distances in comparison with the furthest, starting from the matrix of distances and similarities. In this way, it was possible to build a mapping of distances, and to verify how far is an $i^{\text {th }}$ region from the $\mathrm{n}^{\text {th }}$, pointing out the position of areas with special autonomy in such context (see fig. 1 and 2). 


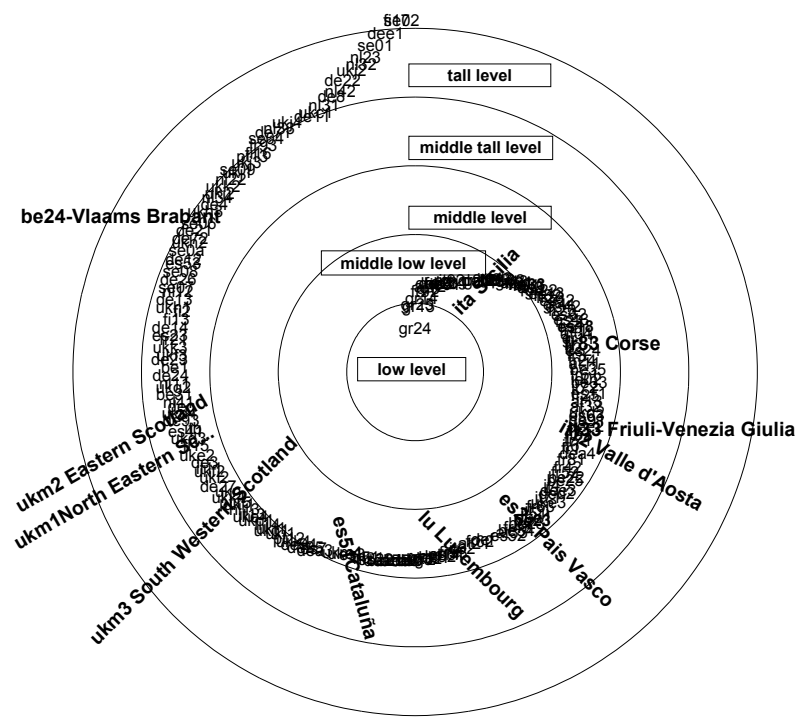

Figure 1: Classification of the 208 regions EU-15 (year 1995) per levels of environmental and economic development.

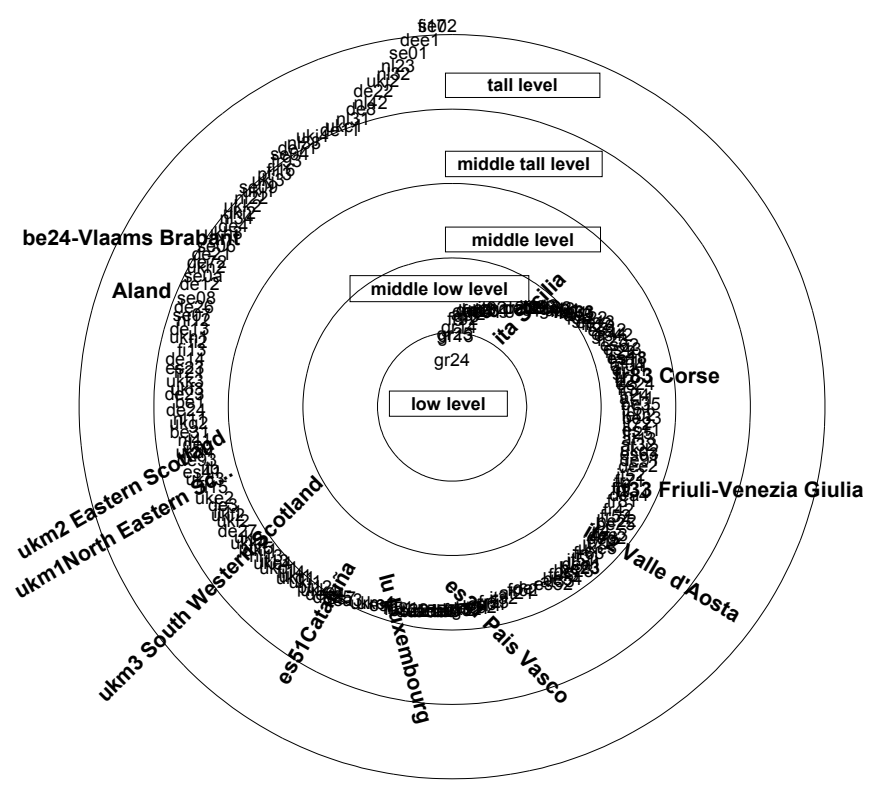

Figure 2: Classification of the 343 regions EU-27 (year 2006) per levels of environmental and economic development. 
In this way, it was possible to point out the levels of the considered development in single autonomous regions, and their distance from the minimum and maximum estimated level.

\section{The results}

Through the analyses carried out, it was possible for us to define the measure of the environmental and economic development. In particular, through the methodologies of classification we generated 5 groups which provided a comprehensive picture of the similarities and dissimilarities among the regions in relation to the economic and environmental indicators considered (see tab. 1).

In this way, it was possible to define the positioning of the regions with special autonomy in comparison to the other regions of the European countries within each cluster.

The analysis we adopted and the particular graphic representation allowed a better reading of the state of economic and environmental development of the analysed regions, with particular attention to the positioning of those with special autonomy and to the change which took place between 1995 and 2006 (see fig. 1 and 2).

By comparing the regions with special autonomy to other regions with similar numerousness of population, it was possible to point out that between 1995 and 2006 the most significant changes were recorded in the first ones. The application of the Wilcoxon test has established the statistical significance of such differences (see tab. 2).

On the base of such considerations, it is possible to confirm that autonomous regions make more significant performances of development than nonautonomous regions, structural conditions being equal. However, in certain cases (like in Sicily or Corse) this doesn't happen. But this result also depends on the national context they belong to.

\section{Conclusions}

With relation to the analyses carried out, it is possible to confirm the assumption that, in the presence of regions with special autonomy, the performances of development present significant indexes of change, both in time and in comparison with regional areas with similar structural features (population). We proved that belonging to a cluster is not representative of the region performances classification with relation to its government. Instead, we found that comparisons in the two lists are significant (most of the autonomous regions present quite good positioning), particularly those comparisons between couples of regions with similar features but with kinds of government and indicators of development that are, in some cases, very different.

The possibility to interpret this phenomenon and the simple reading of the results are encouraging to carry out other studies, hoping that the matrixes of the data and the indicators will be complete. 
Table 1: Results of the cluster analysis and regions with special autonomy in bold.

\begin{tabular}{|c|}
\hline Cluster 1 \\
\hline $\begin{array}{l}\text { fr91 Guadeloupe (FR) - fr92 Martinique (FR) - fr93 French Guiana (FR)- ie01 Border, Midlands and } \\
\text { Western - fr94 Reunion (FR) }\end{array}$ \\
\hline Cluster 2 \\
\hline 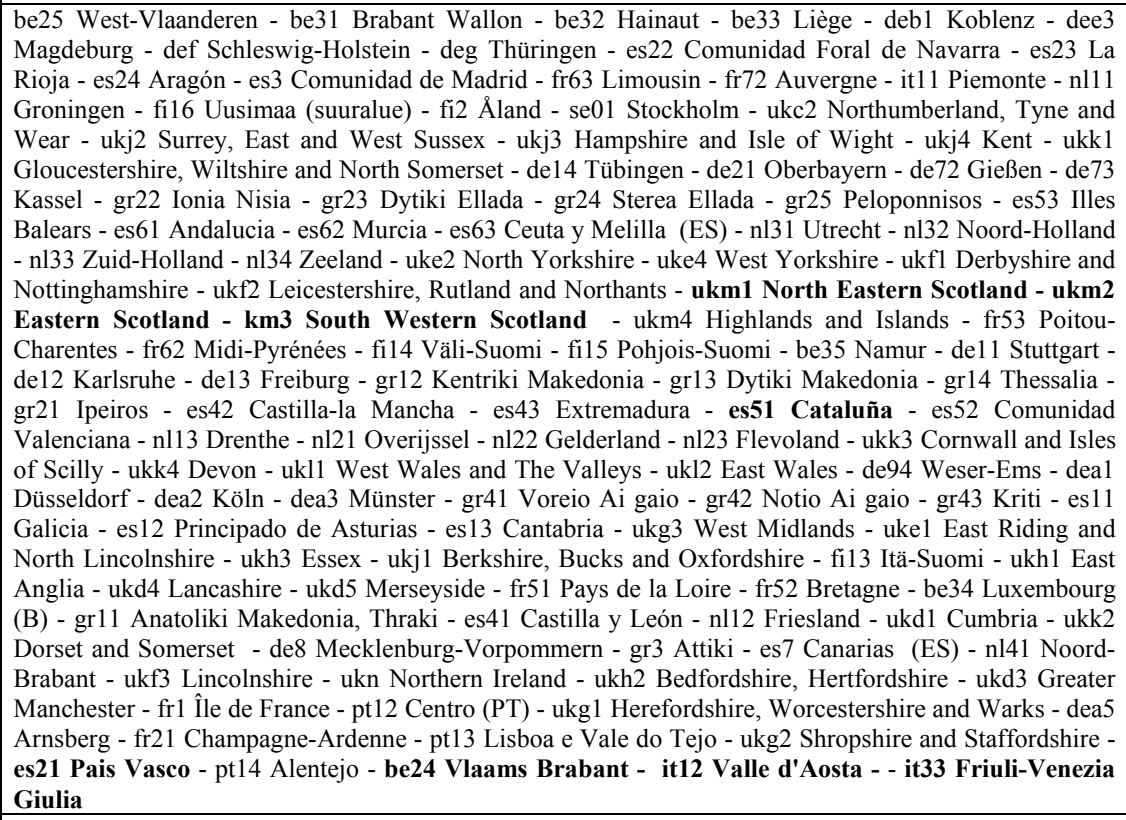 \\
\hline Cluster 3 \\
\hline $\begin{array}{l}\text { at21 Kärnten - at22 Steiermark - at31 Oberösterreich - at33 Tirol - uke3 South Yorkshire - uki1 Inner } \\
\text { London - uki2 Outer London - at32 Salzburg - ie02 Southern and Eastern - at11 Burgenland - at12 } \\
\text { Niederösterreich - at13 Vienna - at34 Vorarlberg - pt2 Açores (PT) - pt3 Madeira (PT) - ukd2 Cheshire }\end{array}$ \\
\hline Cluster 4 \\
\hline $\begin{array}{l}\text { be21 Antwerpen - be22 Limburg (B) - be23 Oost-Vlaanderen - - fr24 Centre - fr25 Basse-Normandie - } \\
\text { fr26 Bourgogne - fr3 Nord - Pas-de-Calais - it52 Umbria - it53 Marche - it6 Lazio - it71 Abruzzo - de3 } \\
\text { Berlin - de4 Brandenburg - de5 Bremen - de6 Hamburg - fr81 Languedoc-Roussillon - fr82 Provence- } \\
\text { Alpes-Côte d'Azur - fr83 Corse - - ita Sicilia - itb Sardegna - lu Luxembourg - pt11 Norte - de23 } \\
\text { Oberpfalz - de24 Oberfranken - de25 Mittelfranken - de26 Unterfranken - fr41 Lorraine - fr42 Alsace - } \\
\text { fr43 Franche-Comté - fr61 Aquitaine - it72 Molise - it8 Campania - it91 Puglia - it92 Basilicata - de71 } \\
\text { Darmstadt - de91 Braunschweig - de92 Hannover - de93 Lüneburg - it13 Liguria - it2 Lombardia - it31 } \\
\text { Trentino-Alto Adige - it32 Veneto - pt15 Algarve - fr23 Haute-Normandie - it4 Emilia-Romagna - it51 } \\
\text { Toscana - de27 Schwaben - fr71 Rhône-Alpes - it93 Calabria - fr22 Picardie }\end{array}$ \\
\hline Cluster 5 \\
\hline $\begin{array}{l}\text { de22 Niederbayern - dea4 Detmold - deb2 Trier - deb3 Rheinhessen-Pfalz - nl42 Limburg (NL) - fi17 } \\
\text { Etelä-Suomi - se02 Östra Mellansverige - se04 Sydsverige - ded1 Chemnitz - ded2 Dresden - ded3 } \\
\text { Leipzig - dee1 Dessau - se07 Mellersta Norrland - se08 Övre Norrland - se09 Småland med öarna - se0a } \\
\text { Västsverige - dec Saarland - se06 Norra Mellansverige - dee2 Halle - ukc1 Tees Valley and Durham }\end{array}$ \\
\hline
\end{tabular}


Table 2: $\quad$ Results of p-value with the Wilcoxon Test on the delta 1995-2006 among regions with similar numerousness of population in relation to the environmental and economic variables - *non-significant test for $\mathrm{p}$ value $>0,05$.

\begin{tabular}{|c|c|c|c|c|}
\hline & Transport & Tourism & Environment & $\begin{array}{l}\text { Economic } \\
\text { aggregates }\end{array}$ \\
\hline $\begin{array}{l}\text { Prov. Vlaams Brabant } \\
\text { Prov. Liège }\end{array}$ & 0,023 & 0,0012 & 0,012 & 0,027 \\
\hline $\begin{array}{l}\text { Pais Vasco } \\
\text { Castilla y León }\end{array}$ & 0,03 & 0,005 & 0,034 & 0,049 \\
\hline $\begin{array}{l}\text { Cataluña } \\
\text { Andalucia }\end{array}$ & 0,076 & 0,041 & 0,023 & 0,038 \\
\hline $\begin{array}{l}\text { Corse } \\
\text { Martinique (FR) }\end{array}$ & $0,89 *$ & 0,0034 & $0,54 *$ & $0,555^{*}$ \\
\hline $\begin{array}{l}\text { Valle d'Aosta } \\
\text { Molise }\end{array}$ & 0,02 & 0,004 & 0,0005 & 0,005 \\
\hline $\begin{array}{l}\text { Friuli-Venezia Giulia } \\
\text { Abruzzo }\end{array}$ & 0,031 & 0,005 & 0,05 & 0,0075 \\
\hline $\begin{array}{l}\text { Sicily } \\
\text { Lazio }\end{array}$ & $0,78^{*}$ & $0,745^{*}$ & $0,56^{*}$ & $0,575^{*}$ \\
\hline $\begin{array}{l}\text { Malta } \\
\text { Luxembourg (Grand-Duché) }\end{array}$ & 0,026 & 0,0042 & 0,015 & 0,03 \\
\hline $\begin{array}{l}\text { Åland } \\
\text { Pohjois-Suomi }\end{array}$ & 0,0056 & 0,021 & 0,034 & 0,049 \\
\hline $\begin{array}{l}\text { North Eastern Scotland } \\
\text { Lincolnshire }\end{array}$ & 0,045 & 0,01 & 0,023 & 0,038 \\
\hline $\begin{array}{l}\text { Eastern Scotland } \\
\text { West Wales and The Valleys } \\
\end{array}$ & 0,048 & 0,013 & 0,034 & 0,049 \\
\hline $\begin{array}{l}\text { South Western Scotland } \\
\text { Gloucestershire, Wiltshire and N.S. }\end{array}$ & 0,0057 & 0,022 & 0,033 & 0,048 \\
\hline & GDP & $\begin{array}{c}\text { Family } \\
\text { accounts }\end{array}$ & Employment & Unemployment \\
\hline $\begin{array}{l}\text { Prov. Vlaams Brabant } \\
\text { Prov. Liège }\end{array}$ & 0,022 & 0,017 & 0,012 & 0,007 \\
\hline $\begin{array}{l}\text { Pais Vasco } \\
\text { Castilla y León }\end{array}$ & 0,044 & 0,039 & 0,034 & 0,029 \\
\hline $\begin{array}{l}\text { Cataluña } \\
\text { Andalucia }\end{array}$ & 0,033 & 0,028 & 0,023 & 0,018 \\
\hline $\begin{array}{l}\text { Corse } \\
\text { Martinique (FR) } \\
\end{array}$ & $0,55^{*}$ & $0,545^{*}$ & $0,54 *$ & $0,535^{*}$ \\
\hline $\begin{array}{l}\text { Valle d'Aosta } \\
\text { Molise }\end{array}$ & 0,01 & 0,005 & $0,50^{*}$ & $0,495^{*}$ \\
\hline $\begin{array}{l}\text { Friuli-Venezia Giulia } \\
\text { Abruzzo }\end{array}$ & 0,007 & 0,065 & 0,06 & 0,055 \\
\hline $\begin{array}{l}\text { Sicily } \\
\text { Lazio }\end{array}$ & 0,587 & 0,567 & 0,456 & 0,235 \\
\hline $\begin{array}{l}\text { Malta } \\
\text { Luxembourg (Grand-Duché) }\end{array}$ & 0,025 & 0,02 & 0,015 & 0,01 \\
\hline $\begin{array}{l}\text { Åland } \\
\text { Pohjois-Suomi }\end{array}$ & 0,044 & 0,039 & 0,034 & 0,029 \\
\hline $\begin{array}{l}\text { North Eastern Scotland } \\
\text { Lincolnshire }\end{array}$ & 0,033 & 0,028 & 0,023 & 0,018 \\
\hline $\begin{array}{l}\text { Eastern Scotland } \\
\text { West Wales and The Valleys }\end{array}$ & 0,044 & 0,039 & 0,034 & 0,029 \\
\hline $\begin{array}{l}\text { South Western Scotland } \\
\text { Gloucestershire, Wiltshire and North } \\
\text { Somerset }\end{array}$ & 0,043 & 0,038 & 0,033 & 0,028 \\
\hline
\end{tabular}




\section{References}

[1] Atkinson A.B., Cantillon B., Marlier E. and Nolan B. (2001), Indicators for social inclusion in the European Union, report presented at Conference on Indicator for social inclusion: making common EU, Antwerp, 14-15 September.

[2] European Commission, Regions: Statistical Yearbook 2003-2007, Lussemburgo.

[3] Horn R.V. (1980), Social indicators: meaning, methods and applications, in International Journal of Social Economics vol.7 n.8 pp.421-460.

[4] Marriem I.C. (1968), Welfare and its measurement, in indicators of social change concept \& measurement ed. By Elanor Berset Sheldon - New York.

[5] Skonieczny G. and Torrisi B (2004) "La misura del benessere sociale nelle regioni europee" in Rivista Italiana di Economia Demografia e Statistica (Gennaio Giugno). 